\title{
GTP-Binding Protein RAD
}

National Cancer Institute

\section{Source}

National Cancer Institute. GTP-Binding Protein RAD. NCI Thesaurus. Code C17781.

GT P-binding protein RAD (308 aa, 33 kDa) is encoded by the human RRAD gene. This protein is involved in the regulation of calmodulin- and voltage-dependent L-type calcium channel subunit alpha-1C-mediated signaling. 